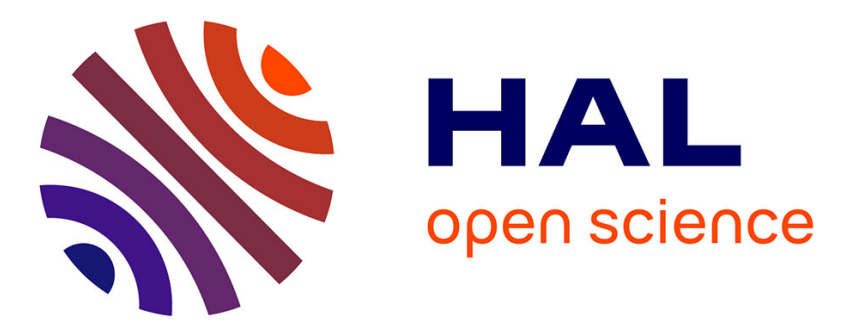

\title{
A Model for Prioritization and Prediction of Impact of Digital Literacy Training Programmes and Validation
}

Nimish Joseph, Arpan Kumar Kar, P. Vigneswara Ilavarasan

\section{To cite this version:}

Nimish Joseph, Arpan Kumar Kar, P. Vigneswara Ilavarasan. A Model for Prioritization and Prediction of Impact of Digital Literacy Training Programmes and Validation. 16th Conference on eBusiness, e-Services and e-Society (I3E), Nov 2017, Delhi, India. pp.227-238, 10.1007/978-3-31968557-1_21.hal-01768498

\section{HAL Id: hal-01768498 \\ https://hal.inria.fr/hal-01768498}

Submitted on 17 Apr 2018

HAL is a multi-disciplinary open access archive for the deposit and dissemination of scientific research documents, whether they are published or not. The documents may come from teaching and research institutions in France or abroad, or from public or private research centers.
L'archive ouverte pluridisciplinaire HAL, est destinée au dépôt et à la diffusion de documents scientifiques de niveau recherche, publiés ou non, émanant des établissements d'enseignement et de recherche français ou étrangers, des laboratoires publics ou privés. 


\title{
A Model for Prioritization and Prediction of Impact of Digital Literacy Training Programmes and Validation
}

\author{
Nimish Joseph ${ }^{1[0000-0002-0560-7325]}$, Arpan Kumar Kar ${ }^{[0000-0003-4186-4887]}$ and P Vigneswara \\ Ilavarasan $^{[0000-0002-9431-3520]}$ \\ Department of Management Studies, IIT Delhi, India \\ ${ }^{1}$ nimishjoseph@gmail.com
}

\begin{abstract}
The Government of India through its various programmes like Digital India aims to provide digital literacy to all its citizens. Towards this mission, National Digital Literacy Mission and Digital Saksharata Abhiyan conducted various training programmes throughout the country. The authors collected details of 5 lakh participants, who successfully completed the training programme and to learn the quality of the training and identify its impact 30,003 participants were interviewed based on a systematic sampling. This study based on the survey and interview identifies a model to predict and validate the impact of similar Digital Literacy training programmes in India. The various components identified in this study were then ranked based on the participant responses using the analytical hierarchy process. The various constructs identified for assessing the quality of training includes conduct, delivery and content, and perceived value. The impact of training was measured using knowledge gained, comfort level achieved and frequency of usage. To identify the impact of training a simple linear regression technique was also used.
\end{abstract}

Keywords: Digital India, Digital Literacy, National Digital Literacy Mission, knowledge, comfort, frequency, training, impact, linear regression, AHP

\section{Introduction}

Digital India is a flagship programme of Government of India with a vision to transform India into a digitally empowered society and knowledge economy. It is evolved with a vision of providing digital infrastructure as a core utility to every citizen, governance and service on demand, and digital empowerment of citizens [1] and to empower the citizens the key areas of focus include digital literacy, digital resources, and collaborative digital platforms. Digital Literacy helps the citizens to exploit digital technologies and thus helping them to lead a better life, becoming economically more secure. The major focus of the government lies in making at least one person from every house hold e-literate. The major achievements of Digital India include National Digital Literacy Mission and Digital Saksharata Abhiyan [2]. There are other activities related to the 
Digital India under various stages of implementation and related transformational processes to achieve the desired objectives [3]. Under the National Digital Literacy Mission, approximately 12.25 lakh persons have been trained and 10 lakh candidates have been certified by National Institute of Electronics \& Information Technology (NIELIT), National Institute of Open Schooling (NIOS), Haryana Knowledge Corporation Limited (HKCL), ICT Academy of Tamil Nadu (ICTACT) and National Institute for Entrepreneurship and Small Business Development (NIESBUD).

In support of above, CSC e-Governance Services India Limited (CSCSPV) is implementing a mass information and communication technology (ICT) literacy programme that provides ICT training to 52.5 lakh citizens in the country. The broad objective of the training is 'to make a person IT literate, so that he or she can operate a computer or any other digital devices like tablet to perform various tasks including the sending and receiving of emails and searching information in the internet. The programme, consists of 20 hours of training, which provides trainees basic familiarity with using computer hardware and IT skills like Internet browsing, emailing etc. After the training, there is an online examination for the trainees. The beneficiaries are selected from households where none of the members in the age group of 14 to 60 years are IT literate. Adequate representation of disadvantaged groups (SC/ST) and below poverty line (BPL) is to be made in the coverage of the programme. The training was mainly provided through CSCSPV's service centres. Some part of the training was also provided through a PPP mode with following partners: adult literacy centers, D/o School Education \& Literacy, MHRD; NIELIT Centers and their accredited Centers; IGNOU Centers and their authorized centers; Rural Self Employment Training Institutes (RSETI); NGOs involved in IT Literacy; and Companies with CSR provisions.

The hands on training received can help the individuals to learn the role of online communities in driving innovation. In particular "peer-produced" knowledge goods like open source software, Wikipedia and crowd-science have been shown to contribute significantly to national growth and productivity [4]. Relevance of social media platforms for professional networking and job portals needs to be introduced to the participants. Digitization has a proven impact on reducing unemployment, improving quality of life, and boosting citizens' access to public services [5].

Governments use ICTs to strengthen political participation of citizens in policy and politics. Online platforms can bring their voices to the higher levels [6]. In a country like India, where the major share of population is below the age of 35 [7], the involvement of youth adds value by participation than its outcome. In fact, online platforms like social media have reinforced the potential for expressive participation. Training programme of this kind is therefore targeted to help the participants become digitally literate. Digital literacy is not just about the ability to handle a software or a digital device, it includes a large variety of complex cognitive, motor, sociological, and emotional skills, which users need in order to function effectively in digital environments [8]. Hence, the evaluation of this training programme includes an impact study which tries to capture information from different perspectives like the level of comfort, confidence and knowledge levels, the frequency of usage and difficulties experienced.

A part of the project is already implemented and a questionnaire was circulated amongst the beneficiaries. 30,003 respondents were contacted for data collection and is 
then used to learn the training programme and its impacts. This study focusses to predict the impact of this training and to project a model for prioritization and prediction of the impact of Digital Literacy Training programmes and its validation.

The survey included various parameters to capture the different aspects of the training and its impacts. The components of training identified include conduct, content and perceived usefulness. The different parameters based on which the impacts of study measured are knowledge gained, comfort level achieved and the frequency of usage post training. Based on the survey results we are framing a model that could be used for the prioritization and prediction of the training impacts. This study identifies if there is any significant relationship between the training provided in terms of conduct, content and perceived value; and the priorities of choices made with respect to impact of the training based on knowledge, comfort and frequency.

\section{$2 \quad$ Literature Review}

Digitization across the globe is creating tremendous opportunities for economies [9] and India is one great example which understood, this need and started preparing the workforce for future to emerge as a technology powerhouse. However, achieving this is not an easy task and involves overcoming of multiple barriers [10]. The rise in internet and mobile subscription in recent years has generated hope but, concrete efforts at multi agency levels are required. For speeding up the economic growth and to improve the human development indices, creativity is a very important resource [11] and digitization practices can help in the creation of such innovative societies. Digital literacy involves many components and establishing the benefits of this diverse view of digital literacies [12] that can help the participants to progress. Digital literacy is not only a key factor in enabling employment and participation in education, but also, a means of acquiring some understanding of the world [13].

Many of the countries in the west have adopted information and communication technologies (ICT) for multiple purposes $[14,15]$. A study conducted in the UK shows how ICT is widely being used in the education sector and it cross examines whether society really desires a transformed, technologically-mediated relation between teacher and learner [16]. ICT training for the residents of Austin emphasizes that such programmes should provide affordable internet, computers and training to its participants [17]. Since last 2-3 years ICT have been widely used for various governance related activities in India [18]. The establishment of portals like myGov [19] and multiple mobile applications have helped the citizens to connect with the government and other service providers. However, to enhance the use of ICT among citizens, the digital literacy should be improved.

\section{Data Collection}

A questionnaire based telephonic survey was conducted for the study using a database of five lakhs people who have completed the training and have received the certificates 
across the country. This was treated as population. The beneficiaries were clubbed on the basis of e-readiness [20] of the state, gender, SC/ST status and religion. A sample of 5000 each from one lakh was selected. The sample selection followed a mix of quota and systematic sampling technique methods. From the database, every eight person was selected. The number eight was arrived at adding digits in the year, 2015, when the project was initially conceptualized. A telephonic survey was carried out for 30, 003 participants using a systematic approach.

A structured questionnaire was used for the survey for data collection from the respondents. The questionnaire was finalized with inputs from the terms of reference and the CSCSPV, especially on the parameters on which the programme could be assessed. Inputs from the stakeholders helped in improving the constructs and the items. The questionnaire collected information on gender, community, religion, age group, employment status, average monthly household income, marital status, educational qualification, language abilities and ICT access (computers/mobiles/tablet/internet connections). Further, the training was assessed with respect to content delivery; impact on individuals' knowledge, comfort, and frequent usage; and benefits for employability and employment, personal usage.

\subsection{Training Details}

The study assessed training on three major components: conduct, delivery and the perceived value. Each of the components was examined with some questions. All three components are interrelated to each other and might impact the outcome of the other. In all three components, the training programme was found to be impacting beneficiaries.

The conduct of the training was understood in terms of regularity, facilities in the class, uninterrupted classes, power supply, and distance of the training center. The study assumed that inadequacy in conduct of the training classes shall result in failure despite a good conduct and might not be perceived as useful by the trainees. The delivery of the training was examined by the clarity of content, pedagogy, easiness of online assessment, and ability to impart what was taught in class to others. The perceived usefulness of the programme was measured by asking possible referrals and willing to attend similar programs. Conduct of the training, delivery of the training and perceived values are identified from the responses and have been explained in the subsequent sections.

Conduct of the training. The conduct of the training was examined using the following indicative questions:

- Was the training regular?

- Did you attend the training regularly?

- Were the training facilities good?

- Were the classes uninterrupted?

- Was the power supply regular to the class?

- Was the training center far from your house? 
Training Delivery. This section questions whether the content is understandable and delivered appropriately. The study used the following indicative questions:

- Did you understand the content?

- Did you like the teaching methods?

- Was the trainer attentive to your queries?

- Were the doubts cleared effectively?

- Did you practice after the theory class?

- Did you find the Online Assessment easy?

Perceived Value. The third component of training examined the perceived usefulness of the course. When someone wants to repeat the similar training programme, it indicates the value of the relevance and usefulness of the content. Referrals for the training programme also indicate the perceived value for the same. This was understood by asking the following questions:

- Do you plan to attend similar trainings?

- Would you like to recommend the same kind of training to others?

- Are you confident of teaching others about computer and internet?

\subsection{Training Impact}

For the 29,834 trained respondents, impact of training on individuals' knowledge, comfort and frequency of usage were also determined. The study tried to understand the impact of the training programme on the following domains: impact on the individual capabilities and the usage of ICT post training. Impact on the individual capabilities covers whether the beneficiaries gained knowledge and comfort in using the stand alone ICTs and the interactive ones. Usage of ICT post training includes the frequent usage of various products.

Impact on individual capabilities. We study the post training responses regarding knowledge and comfort while using standalone and interactive ICTs. Any use of Internet ICTs where request and response of actions are involved is treated as interactive ICTs.

Use of stand-alone ICTs identified whether beneficiaries possess knowledge and feel comfortable using the following indicative questions:

- Basic computer skills (connecting peripherals)

- Using computer/laptop/mobile/smartphone/tablet

- Adding contacts in mobile phone

- Connecting to Wi-Fi in mobile phone/tablet

- Using search engines for information query

- Viewing YouTube and accessing Wikipedia 
It's also important to learn whether the beneficiaries are frequently using or accessing the ICTs learnt from the training programme. The interactive ICTs include but is not limited to:

- Sending and receiving emails

- Using WhatsApp and other social media websites

- Using audio/video calls

- Boking tickets and paying bills online

- Accessing government websites and filling online applications

\section{$4 \quad$ Experimental Details}

Analysis was conducted using the Analytic Hierarchy Process (AHP) on each of the user data followed by a linear regression model to derive the required relationship. The user responses were marked in a scale of 1 to 4 for each of the questions, 1 being the lowest and 4 highest. Based on the users responses mean of the values were derived for all 3 parameters identified for both training and its impacts. After the determination of mean value, AHP was performed for each of the participant to identify the weights and priorities of each component.

The Analytic Hierarchy Process (AHP), introduced by Thomas Saaty (1980), is an effective tool for dealing with complex decision making process [21]. AHP for checking the consistency of the decision maker's evaluations, also incorporates a technique, that can improve the decision making process by reducing the bias. There will be a set of evaluation criteria and choices or alternatives from which the AHP makes the decision of best choice. The evaluation criteria might be contrasting and hence it is not true that some choice which optimizes independent criterion is going to be the best. Rather, the choice which achieves the maximum value amongst others will be declared as the best choice. Based on the decision maker's choice AHP initially assigns weight for every pair of choices. One criteria with a higher weight will have a higher impact on the results compared to others. Further based on the weights, scores are computed for every criteria pairwise. Finally, the AHP combines the criteria weights and the options scores, thus determining a global score for each option, and a consequent ranking [22].

AHP can be considered as a simple, flexible and powerful tool that is capable to translate both qualitative and quantitative evaluations made by the decision maker into a multi criteria ranking. The weights are assigned based on the decision makers choice and hence, making it flexible. However, as the number of criteria and evaluation increases, it requires a large amount of decision making as every pair in a criteria need to be given separate weights. The number of comparisons increase as the criteria increases. The number of pairwise comparisons increases quadratically.

Implementation of the AHP. The first step involved was identifying the hierarchy and also calculating the weighted matrix for each component. Fig. 1 represents the hierarchy for training. It gives the components identified as part of collecting the training details. A hierarchy was also formed based on the identified components that was used to measure the impact. Fig. 2 represents this hierarchy. 


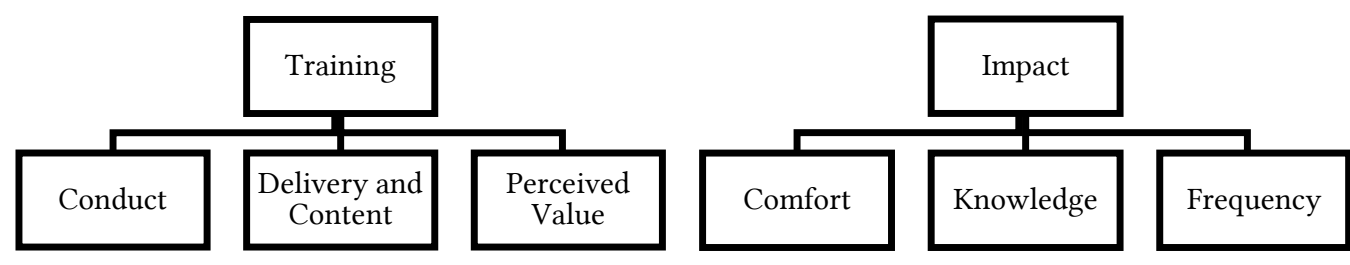

Fig. 1. Hierarchy for Training

Fig. 2. Hierarchy for Impact

The mean values obtained were used to compare the pairwise criteria and was then mapped to the scale of 1 to 9 . Both training and impact have 3 evaluation criteria. For estimation of the individual consistent priorities using the row geometric mean method, the individual vector is obtained by solving the following system [23]. Let $\mathbf{M}$ $=\left(\widetilde{m}_{i j}\right)_{n * n}$, be the judgement matrix

$$
\min \sum_{i=1}^{n} \sum_{j>i}^{n}\left(\ln \widetilde{m}_{i j}-\left(\ln \widetilde{w}_{i}-\ln \widetilde{w}_{j}\right)^{2}\right)
$$

such that $\widetilde{w}_{i} \geq 0$ and $\sum \widetilde{w}_{i}=1$. The solution is obtained by [24]

$$
\widetilde{w}_{i}=\frac{\frac{1}{n} \sqrt{\prod_{j=1}^{n} \widetilde{m}_{i j}}}{\sum_{i=1}^{n} \frac{1}{n} \sqrt{\prod_{j=1}^{n} \tilde{m}_{i j}}}
$$

where $\widetilde{w}_{i}$ is the weight of the decision criteria $i$. To estimate the consistency of parameters geometric consistency index is being used [25]

$$
G C I\left(M^{d_{i}}\right)=\frac{2}{(n-1)(n-2)} \sum_{j>i}^{n}\left(\log \left|\widetilde{m}_{i j}\right|-\left(\log \left|\widetilde{w}_{i}\right|-\log \left|\widetilde{w}_{j}\right|\right)^{2}\right)
$$

Aggregation of individual judgments:

$$
\tilde{m}_{i j}^{(c)}=\prod_{k=1}^{t}\left(\widetilde{m}_{i j}^{(k)}\right)^{\varphi k}
$$

The weighted matrix Y was identified separately for each hierarchy. For example, mean values of user $r_{i}$ for conduct, content and perceived value are 3.4285, 3.285 and 4 respectively. The values here are arrived after performing the above computations. Table 1 gives the weighted matrix $\mathrm{Y}$ for Training data of user $\mathrm{i}_{\mathrm{i}}$.

Table 1. Weighted matrix Y for training: useri

\begin{tabular}{llll}
\hline & conduct & Content & perceived value \\
\hline Conduct & 1 & 1.380952 & 0.396226 \\
Content & 0.72413 & 1 & 0.344262 \\
perceived value & 2.52381 & 2.904762 & 1 \\
\hline
\end{tabular}


To collect obtain the normalized weights for each component geometric mean is calculated for each row. The normalized weights were then used to prioritize different components. Conduct, content and perceived value were ranked based on their contribution to the user responses. Table 2 denotes the prioritization of various components with respect to the training of user $\mathrm{i}_{\mathrm{i}}$.

Table 2. Prioritization of training components: useri

\begin{tabular}{ccc}
\hline Conduct & content & perceived value \\
\hline 0.241279 & 0.185659 & 0.573062 \\
\hline
\end{tabular}

The authors performed a linear regression to develop a model to predict the components of impact based on the components of Training. The training components acted as the independent variables and the impact components as the dependent variable. Subsequent section discuss the findings of this regression model using SPSS [26].

\section{$5 \quad$ Results and Discussions}

The various findings of performing regression using SPSS are as follows. The independent variables entered to generate the regression chart for dependent variables knowledge gained, comfort level achieved and frequency of usage are perceived value and content. Table 3 and Table 4 gives the simple correlation (R) and variation in dependent variables that can be explained by the independent variable (R Square). This also gives the F Test value which explains the relevance of linear relationship between two variables for different models.

Table 3. Model Summary

\begin{tabular}{lllll}
\hline Model & $\mathrm{R}$ & R Square & $\begin{array}{l}\text { Adjusted } \\
\text { Square }\end{array}$ & $\begin{array}{l}\mathrm{R} \\
\text { Std. Error of the Esti- } \\
\text { mate }\end{array}$ \\
\hline 1 & $.173 \mathrm{a}$ & .030 & .030 & .10496946 \\
2 & $.066 \mathrm{a}$ & .004 & .004 & .07748532 \\
3 & $.137 \mathrm{a}$ & .019 & .019 & .11440536 \\
\hline
\end{tabular}

Table 4 give the significance of this F Change where the dependent variable varies for model 1, model 2 and model 3 as knowledge gained, comfort level achieved and frequency of usage respectively.

Table 4. Model Summary change statistics

\begin{tabular}{llllll}
\hline Model & R Square Change & F Change & df1 & df2 & Sig. F Change \\
\hline 1 & .030 & 461.121 & 2 & $29831 \mathrm{a}$ & .000 \\
2 & .004 & 64.586 & 2 & $29831 \mathrm{a}$ & .000 \\
3 & .019 & 286.541 & 2 & $29831 \mathrm{a}$ & .000 \\
\hline
\end{tabular}

a. Predictors: (Constant), Perceived Value, Content

Table 5, analysis of variance explains how well prediction is possible and whether the regression equation fits the data or not. Here, dependent variable b used for model 1 is 
the knowledge gained, for model 2 is the comfort level achieved and for model 3 is the frequency of usage.

Table 5. Analysis of Variance

\begin{tabular}{|c|c|c|c|c|c|c|}
\hline \multicolumn{2}{|c|}{ Model } & Sum of sq. & Df & Mean sq. & $\mathrm{F}$ & Sig. \\
\hline \multirow{3}{*}{1} & Regression & 10.162 & 2 & 5.081 & 461.12 & $.000 b$ \\
\hline & Residual & 328.695 & 29831 & .011 & & \\
\hline & Total & 338.857 & 29833 & & & \\
\hline \multirow{3}{*}{2} & Regression & .776 & 2 & .388 & 64.586 & $.000 b$ \\
\hline & Residual & 179.105 & 29831 & .006 & & \\
\hline & Total & 179.880 & 29833 & & & \\
\hline \multirow{3}{*}{3} & Regression & 7.501 & 2 & 3.750 & 286.54 & $.000 b$ \\
\hline & Residual & 390.446 & 29831 & .013 & & \\
\hline & Total & 397.946 & 29833 & & & \\
\hline
\end{tabular}

Table 6 gives the regression coefficients and its significance along with the intercept. It helps us to derive the model for linear regression. The equations derived towards the end of this section are calculated. The residual values derived also gives clear indication on why this model is important.

Table 6. Coefficients

\begin{tabular}{|c|c|c|c|c|c|c|c|}
\hline \multicolumn{2}{|c|}{ Model } & \multicolumn{2}{|c|}{ Unstandardized Coefficients } & \multicolumn{2}{|c|}{ Standardized coefficients } & \multirow[t]{2}{*}{$\mathrm{T}$} & \multirow[t]{2}{*}{ Sig. } \\
\hline & & B & Std. Error & Beta & & & \\
\hline \multirow[t]{3}{*}{1} & (Constant) & .415 & .004 & & 103.354 & & .000 \\
\hline & Content & -.079 & .008 & -.077 & -9.986 & & .000 \\
\hline & Perceived Value & .080 & .006 & .111 & 14.330 & & .000 \\
\hline \multirow[t]{3}{*}{2} & (Constant) & .343 & .003 & & 115.712 & & .000 \\
\hline & Content & .063 & .006 & .085 & 10.775 & & .000 \\
\hline & Perceived Value & .019 & .004 & .036 & 4.642 & & .000 \\
\hline \multirow[t]{3}{*}{3} & (Constant) & .243 & .004 & & 55.550 & & .000 \\
\hline & Content & .016 & .009 & .015 & 1.864 & & .062 \\
\hline & Perceived Value & -.099 & .006 & -.127 & -16.292 & & .000 \\
\hline
\end{tabular}

Table 7 indicates the variable that are excluded and are not used as predictors in the model. This also explains the significance of excluded variable and its partial correlation value for the dependent variables knowledge gained, comfort level achieved and frequency of usage using model 1, model 2 and model 3 respectively. Figure 3 and Figure 4 depicts the histogram for dependent variable knowledge gained where the regression standard residual is mapped with frequency and P-P plot of regression standardized residual respectively. Figure 5 and 6 are for comfort level achieved and Figure 7 and Figure 8 are for the frequency of usage.

Table 7. Excluded Variables

\begin{tabular}{|c|c|c|c|c|c|c|}
\hline \multirow{2}{*}{\multicolumn{2}{|c|}{ Model }} & \multirow[t]{2}{*}{ Beta In } & \multirow[t]{2}{*}{$\mathrm{T}$} & \multirow[t]{2}{*}{ Sig. } & \multirow[t]{2}{*}{ Partial Correlation } & \multirow{2}{*}{$\begin{array}{l}\text { Collinearity Statistics } \\
\text { Tolerance }\end{array}$} \\
\hline & & & & & & \\
\hline 1 & Conduct & $3921.646 a$ & .11 & .908 & .001 & 2.797E-014 \\
\hline 2 & conduct & $-12429.6 a$ & -.36 & .719 & -.002 & 2.797E-014 \\
\hline 3 & Conduct & 4738.117a & .13 & .890 & .001 & 2.797E-014 \\
\hline
\end{tabular}




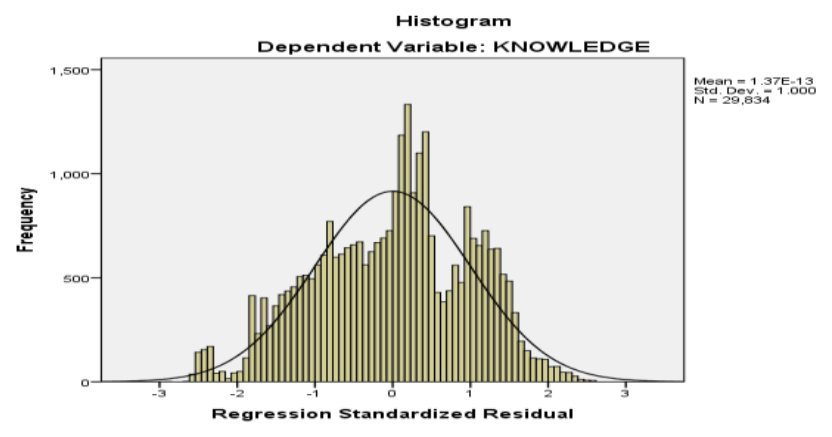

Fig. 3. Histogram for Dependent Variable Knowledge

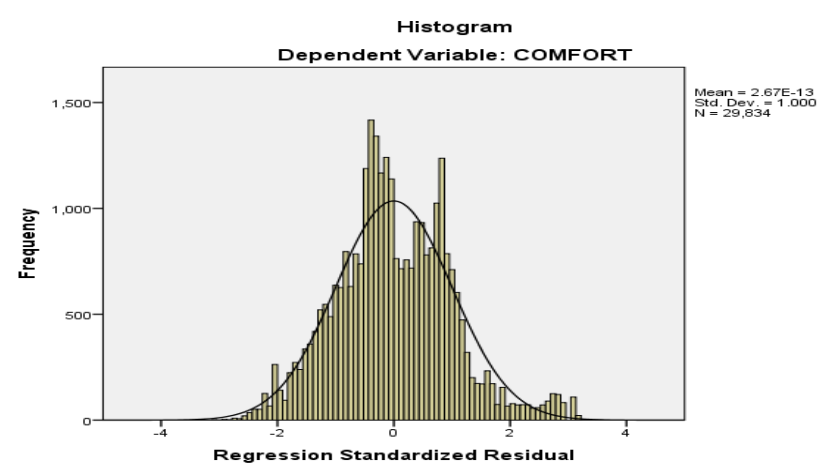

Fig. 5. Histogram for Dependent Variable Comfort

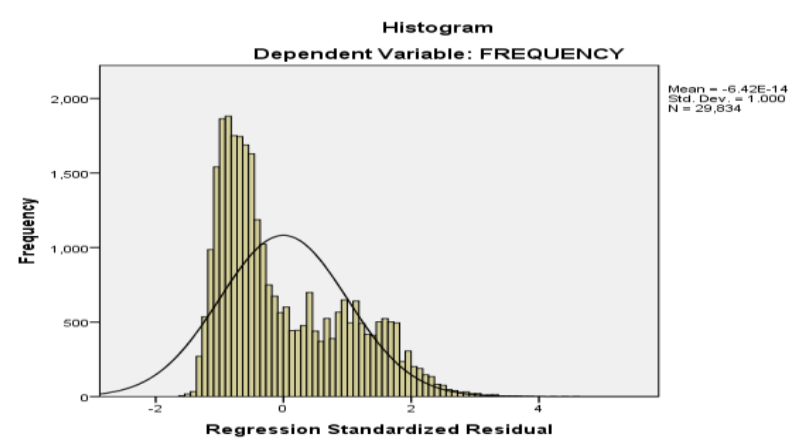

Fig. 7. Histogram for Dependent Variable Frequency

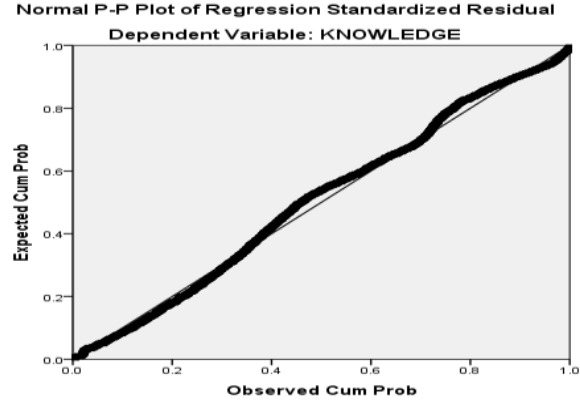

Fig. 4. Normal P-P plot of Regression Standard Residual

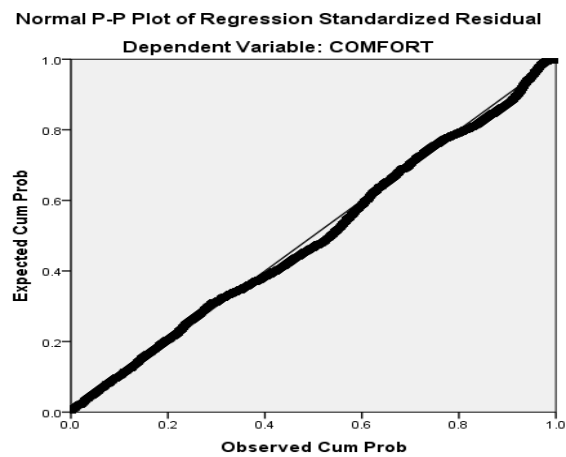

Fig. 6. Normal P-P plot of Regression Standard Residual

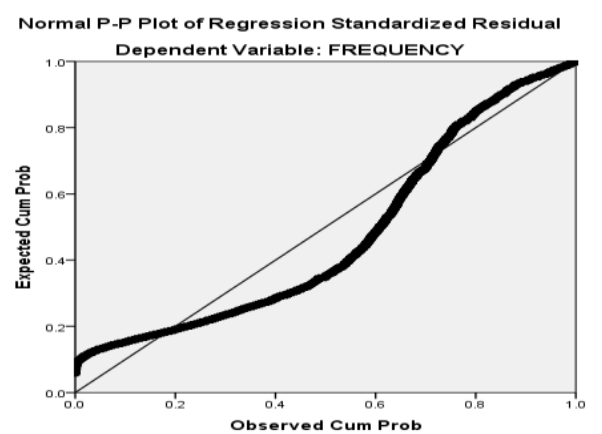

Fig. 8. Normal P-P plot of Regression Standard Residual

The regression model developed above was successful in identifying relationships between the dependent and independent variables and the various relationships obtained is as follows:

- $\quad$ Knowledge $=0.415-0.079$ Content +0.080 Perceived Value,

- Comfort $=0.343+0.063$ Content +0.019 Perceived Value, 
- $\quad$ Frequency $=0.243+0.016$ Content -0.099 Perceived Value

\section{Conclusions}

India, since independence is trying to achieve self-reliance and is looking forward to a 'Digital Revolution'. Many scientific and technical institutes and initiatives were started to make supreme contributions in this area. To become digitally literate, the programmes like this must reach every corner of the country and must bridge this digital divide. Learning and use of ICTs must also provide the users employment opportunity. The trainings like this have a great impact in our society and therefore, this study is focused to predict the impacts based on training and its components.

This study was successful in capturing the linear relationship for various components of digital literacy training with its impacts. This model can help us to predict what the impact of training could be based on the conduct, content and value perceived from the training. Knowledge, comfort and frequency - plots were obtained against the independent variables. The p-value statistics indicate that the results obtained are significant. This study also gives a model of how the survey results can be converted as a prediction model based on the priorities of user input. AHP used in this study helped the authors to identify the user priorities and also to determine its value against the responses, considering the differentiation from other responses. The successful combination of AHP and linear regression model can thus help in identifying a prediction model based on the survey responses. Hence, this study gives a model for prioritization and prediction of impact of digital literacy training programmes and validation.

\section{References}

1. Ministry of Electronics \& Information Technology, Government of India, in Digital India Programme, http://www.digitalindia.gov.in/, last accessed 2016/09/16.

2. Prasad, R. S, Digital India - The Vision and the Mission, https://blog.mygov.in/editorial/digital-india-the-vision-and-the-mission/, last accessed 2016/09/08

3. Sharma, S. K, Lama, V., and Goyal, N: Digital India: A Vision Towards Digitally Empowered Knowledge Economy. Indian Journal of Applied Research 5(10), 715-716 (2016).

4. Nagaraj, A: Essays on the Impact of Digital Information on Innovation, http://papers.ssrn.com/ sol3/papers.cfm?abstract_id=2810758, last accessed 2016/09/30.

5. Sabbagh, K., Friedrich, R., El-Darwiche, B., Singh, M., Ganediwalla, S. and Katz, R.: Maximizing the impact of digitization. The Global Information Technology Report 2012: Living in a Hyperconnected World, 121-133(2012).

6. Thijssen, P. and Van Dooren, W.: Going online. Does ICT enabled-participation engage the young in local governance?" Local Government Studies 42(5), 842-862(2016).

7. Office of the Registrar General \& Census Commissioner, Census of India, 2011, http://www.censusindia.gov.in/, last accessed 2016/11/28.

8. Ghosh, S.B. and Das, A.K.: Information literacy initiatives in India with special reference to emerging knowledge economy. In International Conference on Information Literacy (icil 2006), Kualalumpur, Malaysia, 12 pages(2006). 
9. Chambers, J.: Bringing Digital India To Life. Business Today 26(1), 52-54(2017).

10. Khokhar, A. S.: Digital Literacy: How Prepared Is India to Embrace It?. International Journal of Digital Literacy and Digital Competence (IJDLDC) 7(3), 1-12(2016).

11. Khandwalla, P.: Designing a creative and innovative India. International Journal Of Human Resource Management 25(10), 1417-1433(2014).

12. Lankshear, C. and Knobel, M.: Digital literacies: Concepts, policies and practices 30. Peter Lang (2008).

13. Martin, A. and Grudziecki, J.: DigEuLit: concepts and tools for digital literacy development. Innovation in Teaching and Learning in Information and Computer Sciences 5(4), 119(2006).

14. Mitrović, Đ.: Broadband Adoption, Digital Divide, and The Global Economic Competitiveness Of Western Balkan Countries. Ekonomski Anali / Economic Annals 60(207), 95115(2015).

15. Chew, H.E., Ilavarasan, P.V. and Levy, M.R.: The economic impact of information and communication technologies (ICTs) on microenterprises in the context of development. The Electronic Journal of Information Systems in Developing Countries, 44 (2010).

16. Livingstone, S.: Critical reflections on the benefits of ICT in education. Oxford review of education 38(1), 9-24 (2012).

17. Richie Jr.: Digital Inclusion. Journal of Housing \& Community Development 72(4), 6-9 (2015).

18. Marathe, M., O'Neill, J., Pain, P. and Thies, W.: ICT-Enabled Grievance Redressal in Central India: A Comparative Analysis. In Proceedings of the Eighth International Conference on Information and Communication Technologies and Development (ICTD '16). ACM, New York, NY, USA, 4 (2016).

19. Lamba, A., Yadav, D. and Lele, A.: CitizenPulse: A Text Analytics framework for Proactive e-Governance-A Case Study of mygov. in. In Proceedings of the 3rd IKDD Conference on Data Science 2016, 16. ACM (2016).

20. Government of India, Department of Information Technology, India e-Readiness Assessment Report 2008, http://meity.gov.in/sites/upload_files/dit/files/e-ReadinessReport_230410.pdf, last accessed 2016/11/28.

21. Satty, T.L.: The analytical hierarchy process: planning, priority setting, resource allocation. RWS publication, Pittsburg (1980).

22. Mocenni, C., Casini, M., Paoletti, S., Giordani, G., Viaroli, P. and Comenges, J.M.Z.: A Decision Support System for the management of the Sacca di Goro (Italy). In Decision Support Systems for risk-based management of contaminated sites.1-24. Springer US (2009).

23. Kumar Kar, A. and Kumar Pani, A.: How can a group of procurement experts select suppliers? An approach for group decision support. Journal of Enterprise Information Management 27(4), 337-357(2014)

24. Crawford, G. and Williams, C.: A note on the analysis of subjective judgment matrices. Journal of Mathematical Psychology 29(4), 387-405(1985).

25. Aguaron, J. and Moreno-Jiménez, J.M.: The geometric consistency index: Approximated thresholds. European journal of operational research 147(1), 137-145(2003).

26. Norušis, M.J.: SPSS/PC+ for the IBM PC/XT/AT. 1. SPSS(1986). 